\title{
Cuatro escenarios para entrevías-Tarragona. ¿Cabría una dinámica dominante?
}

\author{
Juan Manuel Zaguirre Fernández \\ Arquitecto
}

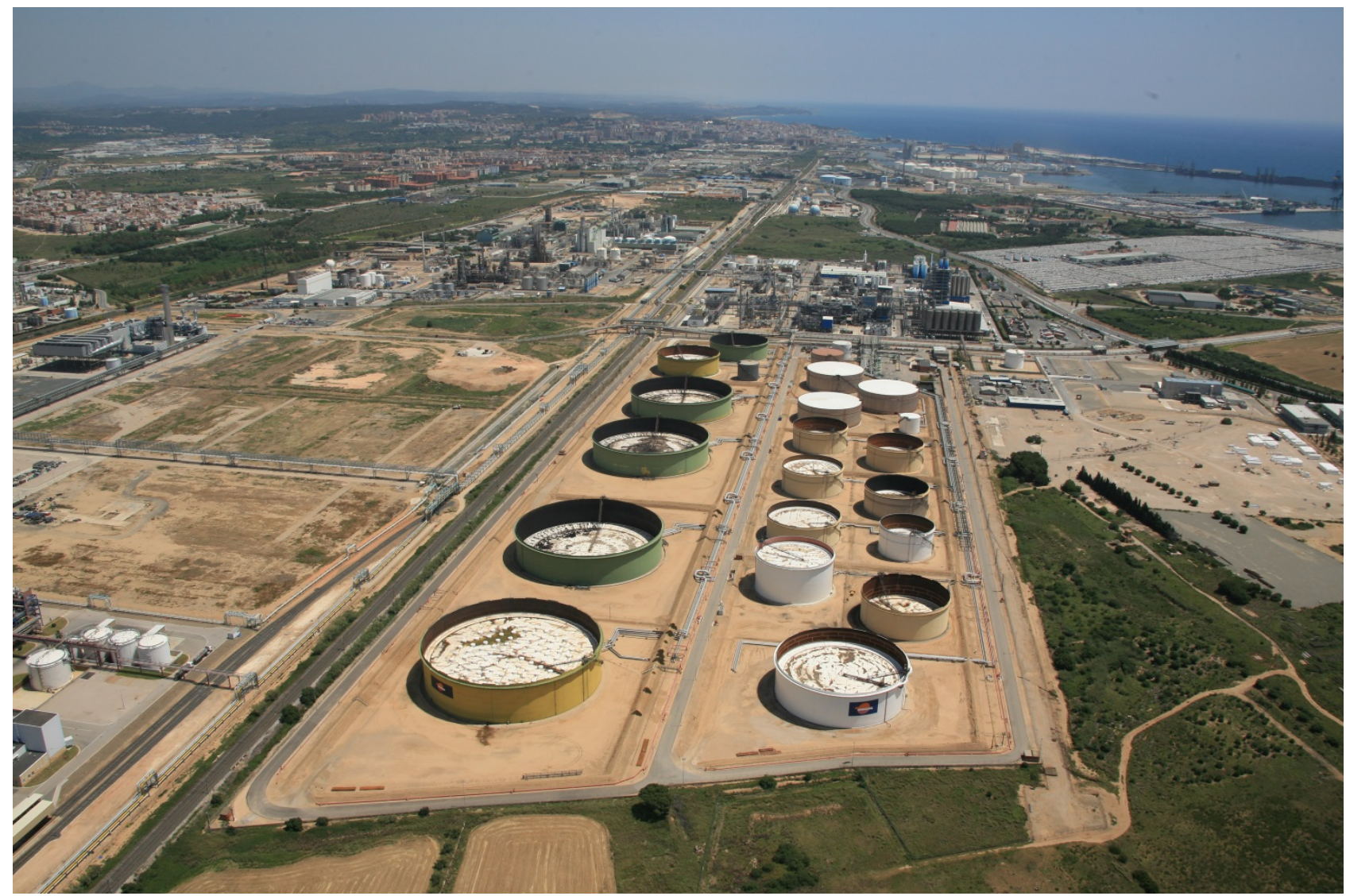

\section{Resumen}

Esta investigación se incorpora a la búsqueda del modelo territorial que de sentido a este mundo completo que es el Camp de Tarragona, donde ENTREVÍAS reclama un protagonismo merecido y poco reconocido. A través de posicionamientos previos sobre episodios urbanísticos en torno a la marginalidad, que han influido en la imagen fabricada de la ciudad, se reivindican valores urbanos perceptibles al poner de relieve valías en suelos expectantes y discontinuidades urbanas, surgidas por erráticos desarrollos urbanísticos que han redibujando paulatinamente los espacios de relación en función de las necesidades del momento. La marginal implantación industrial, la residencia periférica, el puerto en expansión, las infraestructuras vertebradoras y los atributos urbanos en ENTREVÍAS son escenarios válidos para profundizar sobre procesos urbanos que reconocemos como habituales. Perspectivas más allá de los escenarios demandan cautela ante una precipitada organización metropolitana para este ámbito territorial de unidades autónomas que conviven en un complejo equilibrio poliédrico.

Palabras clave: Secuencia, marginal, discontinuidad, urbanidades.

\section{Abstract}

This emerging investigation joins the search of a territorial model to give meaning to this "complete world" which is the Tarragona central area, where ENTREVIAS claim a deserved prominence that as yet unrecognized. Through previous positions on episodes around urban marginality, which have influenced the manufactured image of the city, it is hoped to reclaim urban values by the importance of uncharted zones, discontinuous areas after the erratic development on gradually redrawing urban spaces based on the relative needs of the moment. The "informal" 
industrial plants, peripheral residential areas, expanding port, infrastructures that condition the territory and the urban attributes on ENTREVIAS can be the scenarios to detect urban processes that we recognize as usual. The conclusions of this article urge caution against a hasty metropolitan organization for this territory of independent living units in a polyhedral complex balance. 


\section{Antecedentes.}

De momento el debate abierto en torno al Camp de Tarragona y su definición no arroja determinaciones concluyentes sobre dinámicas urbanas dominantes. Las más creíbles comparten un mismo emplazamiento en el que convergen muchas miradas atentas -el Poniente de Tarragona- al que denomino formal e intencionadamente ENTREVÍAS. Un uso agrícola intensivo, sendos trazados de ferrocarril, y el delta del río Francolí ayudan a esquivar hasta 1952 cualquier pretensión urbana de este territorio pese a disponer de un eje viario fundamental como es la N-340. Tarragona desde el 1922 había fijado su interés en la ampliación de su casco urbano mediante la prolongación de la Rambla y también en la construcción de algunos edificios singulares (Fábrica de Tabacos, Escuela del Trabajo, la Casa-Bloque, Preventorio de La Savinosa, Cuartel de Infantería). No fue hasta 1960 cuando el Plan Monravà jerarquiza y regula la oportunidad y el interés especulativo por los territorios más allá del Francolí. Posteriores planeamientos generales (Plan de Infraestructuras 1973, Plan Cantallops 1983) han seguido moldeando este territorio hasta su actual desarrollo y a las puertas de un nuevo y controvertido Plan de Ordenación Urbana.

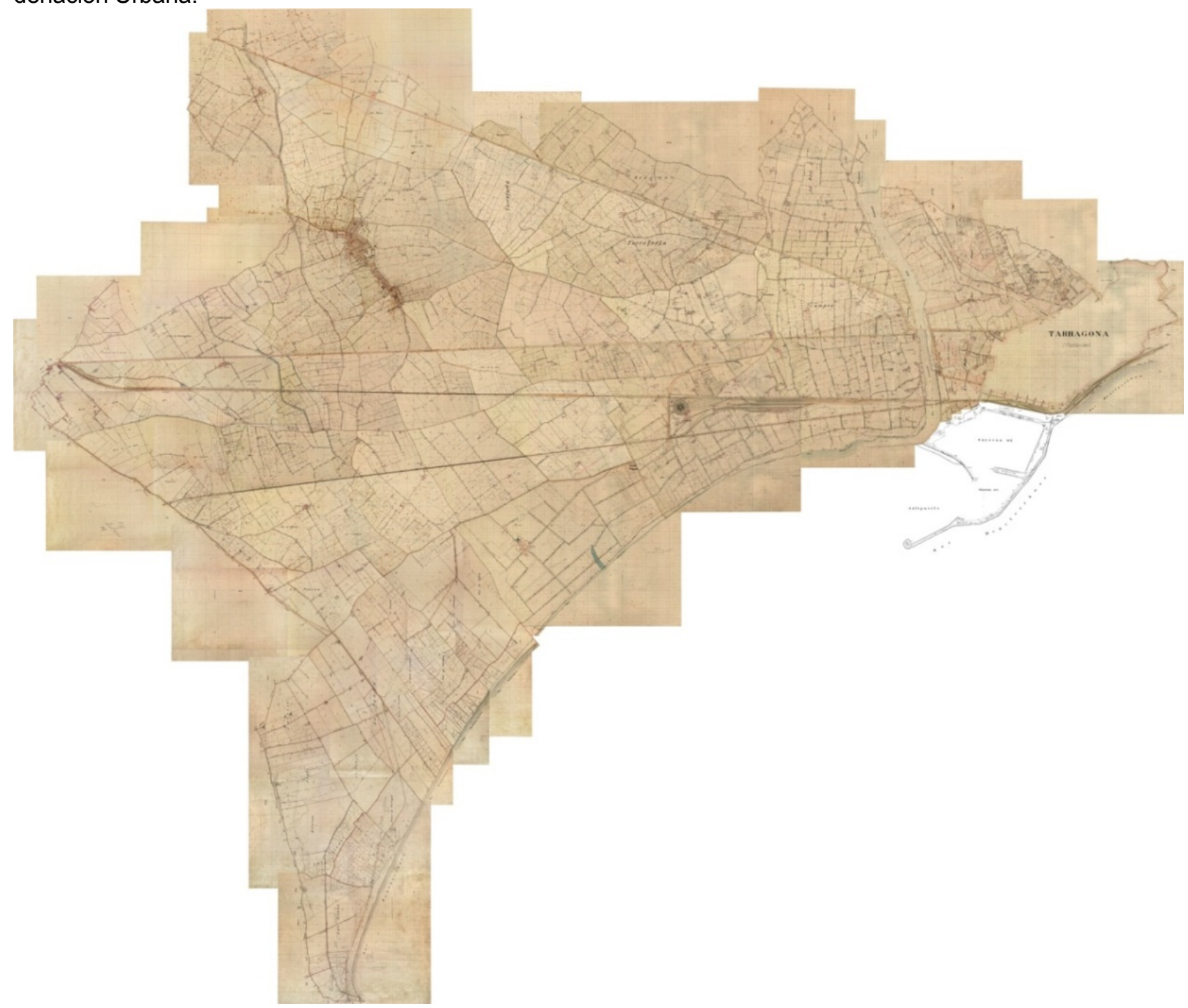

Fig. 1. Plano de conjunto catastral del ámbito Vila-seca, La Pineda, La Canonja, Entrevías y Horta Gran, 1936-1939.

Fuente: Elaboración propia a partir de la digitalización y montaje de planillas catastrales del Arxiu Històric de Tarragona

\section{Objetivos.}

Como objetivos fundamentales se establecen el análisis, la realidad y las expectativas del sector industrial ENTREVÍAS-TARRAGONA y su entorno de influencia más inmediato, profundizando en los desafíos urbanísticos que aguardan a este territorio evitando confiar a un devenir incierto los necesarios equilibrios entre unas necesidades urbanas, sociales y económicas en constante mutación ideológica y tecnológica. Se cuestiona la segre- 
gación y marginalización de los espacios industriales, y en concreto en ENTREVÍAS, para reivindicar las potencialidades inherentes de emplazamientos muy marcados por la distancia social entre su actividad industrial e infraestructura necesaria, su huella histórica y su crónica actual. Un autismo territorial provocado y amparado en el tiempo que esconde la impunidad de su secuencia urbanística acorde a sus dimensiones tangibles e intangibles. Sería deseable que en el mayor desarrollo de estas hipótesis surjan nuevas perspectivas más allá de los escenarios planteados que nos anuncien los caminos a seguir para entender y comprender el esfuerzo territorial que requiere Tarragona.

\section{Metodología y posicionamientos previos.}

Tras una compilación inicial y primeras exploraciones sobre la secuencia urbanística del sector ENTREVIESTARRAGONA se abren nuevos caminos de investigación. Inédita información catastral (1936-1939) en torno al valor del territorio, previo a su alteración, y oportunas manipulaciones gráficas de planimetrías actuales permiten identificar una realidad, todavía en parte presente, de aquella huella agraria tan representativa del Camp y de los episodios urbanísticos que la sucedieron. Este material cartográfico muestra un territorio impregnado de una parcelación muy característica y fraccionada, en función de la fertilidad del terreno, que abasteció de suelo al impulso desarrollista ${ }^{1}$ del momento que mostró un interés en Tarragona sólo equiparable, en ese momento, a otros emplazamientos como Gijón y Sevilla.
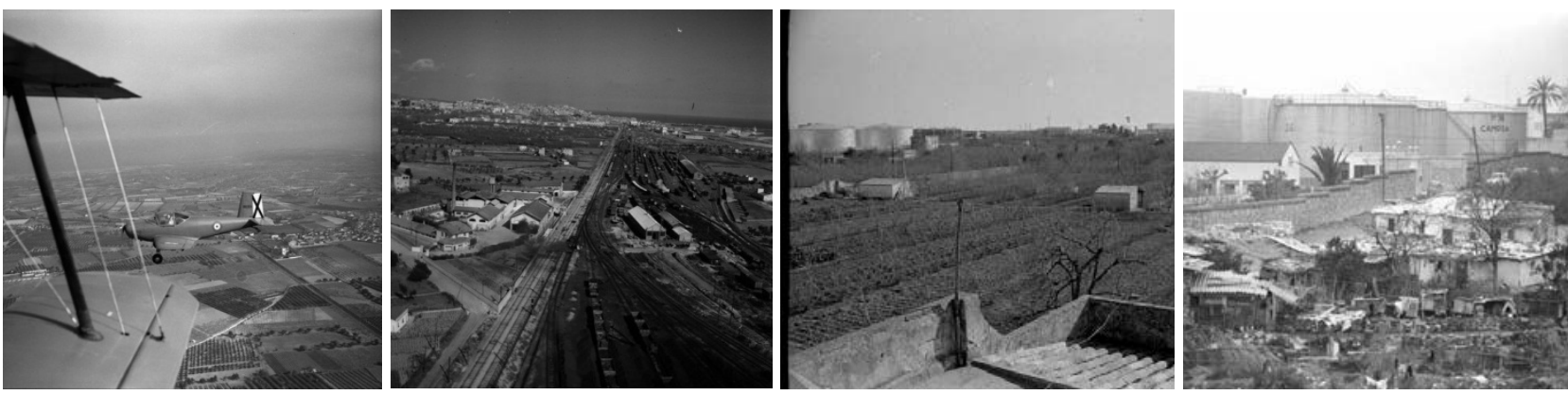

Fig. 2. Selección de imágenes del vaciado en archivos fotográficos históricos (1950-1955) Fuente: Arxiu Canadell. Tarragona

Como paso previo a la proposición de hipótesis, esta incipiente investigación determina unas líneas de trabajo en torno a la información que han puesto de relieve los materiales documentales consultados y las primeras exploraciones iniciadas. Estos mecanismos de reconocimiento previo han sugerido atribuir lecturas alternativas e inéditas sobre este territorio. A modo enunciativo la investigación establece los siguientes posicionamientos previos que se acompañan de una selección de material gráfico producido a tal efecto y que ilustran las argumentaciones presentadas en esta comunicación.

\subsection{La industrialización marginal como forma de crecimiento urbano.}

Los impulsos desarrollistas del momento, que alteraron la morfología territorial de ENTREVÍAS, dieron lugar a tejidos peri-urbanos de características marginales pero no siempre vinculados a precarias condiciones exclusivamente residenciales. Estos espacios de la nueva Tarragona, marcados por una cultura industrial dominante y con escasez urbanística, todavía no son ESPACIOS DE PRECISIÓN (Sennet, 1997) y por consiguiente generan distancia y tensión en "la imagen fabricada de la ciudad" (Usemoto, 2004). La producción industrial tradicionalmente ha ocupado franjas de terreno condenadas al olvido y a la exclusión urbanística. Llegados a este punto merece especial interés abordar estos procesos de industrialización marginal en el territorio bajo ópticas de análisis, diagnosis e intervención, adaptadas a este fenómeno de crecimiento urbano que se fundamenta en características estructurales de implantación marginal ${ }^{2}$. Todo ello sin menospreciar su valía, porque no por carecer

\footnotetext{
${ }^{1}$ El 10 de diciembre de 1959 el BOE publica un decreto que autoriza a la Dirección General de Urbanismo la expropiación de los terrenos destinados al nuevo polígono industrial "Francoli". El Decreto argumenta esta medida en aplicación del Plan de Urgencia de Descongestión Industrial de Barcelona de 1959. Dice textualmente "La situación privilegiada y las ventajas esenciales que ofrece la ciudad de Tarragona para desarrollar el Plan del Gobierno de Urgencia de Descongestión Industrial de Barcelona, condiciones que han sido reconocidas y aprovechadas por las industrias que en un limitado período de tiempo se están instalando ya que cuentan con un estratégico puerto, una excelente red de comunicaciones, energía eléctrica y demás circunstancias favorables, aconsejan establecer en la misma un polígono industrial". Extracto del libro La Industrialització de Tarragona (1957-1971) i les seves circumstàncies. Autor, Llop Tous, J. Ed. Arola. Tarragona. 2002.
}

${ }^{2}$ La actividad económico-industrial, entendida también como fenómeno social de primer orden, puede verse alterada en caso de que su im-

Cuatro escenarios para entrevías-Tarragona. ¿Cabría una dinámica dominante? Juan Manuel Zaguirre Fernández. DOI 10.14198/i2.2015.03.01 
de regulación les falta interés urbanístico. Considerar a la industrialización marginal como forma de crecimiento urbano es reconocer el interés de las colisiones, encuentros e intersecciones en la secuencia urbanística de este fenómeno. Reconducir esta situación anómala también implica reconocer el valor de decisiones improvisadas, no planificadas, pero admisibles. Hoy, en un momento de incertidumbre territorial, el motor industrial químico y residencial periférico de Tarragona presenta un claro estancamiento y en paralelo con evidentes tendencias a la "tercialización" del tradicional ámbito industrial al otro lado del Francolí. La actual escasa heterogeneidad industrial de ENTREVÍAS podría convertirse en un lastre en caso de un estancamiento productivo de la química, dejando inertes los espacios intersticiales dispersos pensados para acoger viejas expectativas.

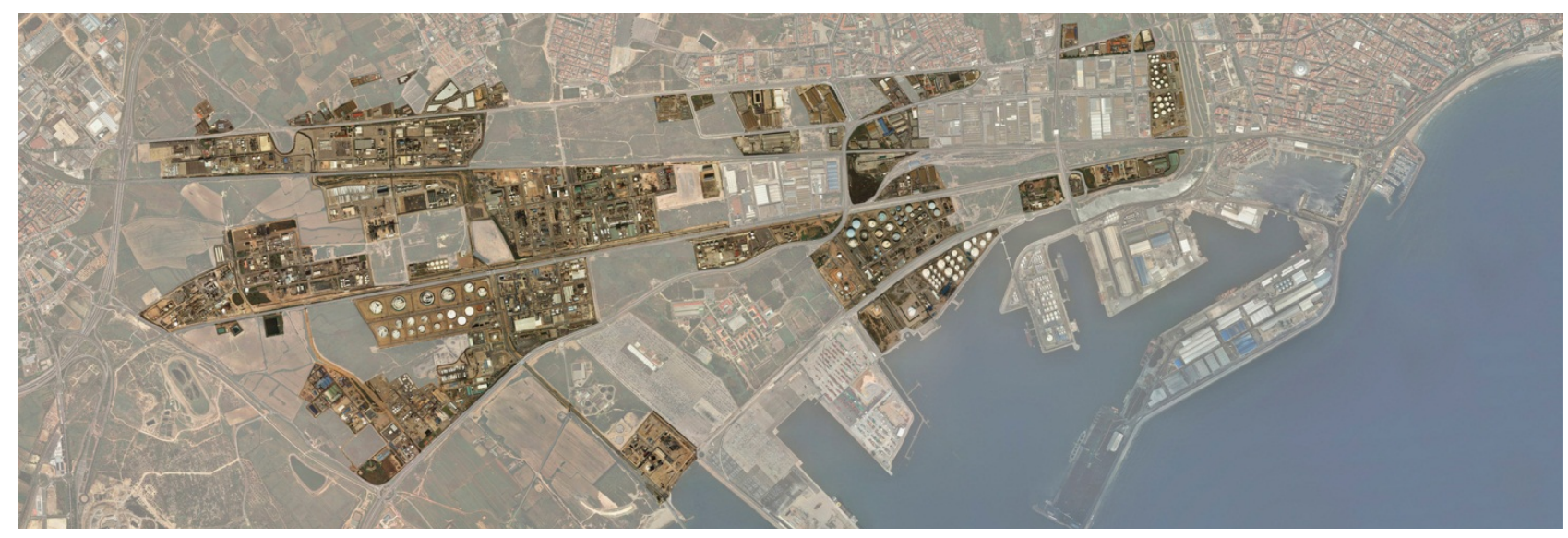

Fig. 3. Ortofotoplano modificado que ilustra el alcance del fenómeno de la "industrialización marginal” en ENTREVÍAS. Fuente: Elaboración propia a partir de ortofotoplanos del ICC (2010)

\subsection{El valor de lo "No Urbanizado" en ENTREVÍAS.}

Ante la clara preeminencia del territorio NO URBANIZADO en ENTREVÍAS, por su extensión y riqueza, son múltiples sus aspectos amables que inciden positivamente en la percepción global de este enclave. Es una consecuencia directa de esta implantación industrial dispersa sin excesivas cesiones y de errático desarrollo. Hoy prevalece como una huella territorial escasamente alterada que reclama su protagonismo y se resiste a seguir expectante. Paralelamente también influye sobre los barrios residenciales de PONENT (Riu Clar, Torreforta, Camp Clar y Bonavista), que siguen atrapados bajo una discontinuidad urbana persistente y que todavía no han resuelto los sucesivos Planes Generales completados y vigentes.

plantación en el territorio no reúna las condiciones de parcelación $(P)$, urbanización $(U)$ y edificación $(E)$ necesarias para su canónico funcionamiento. 


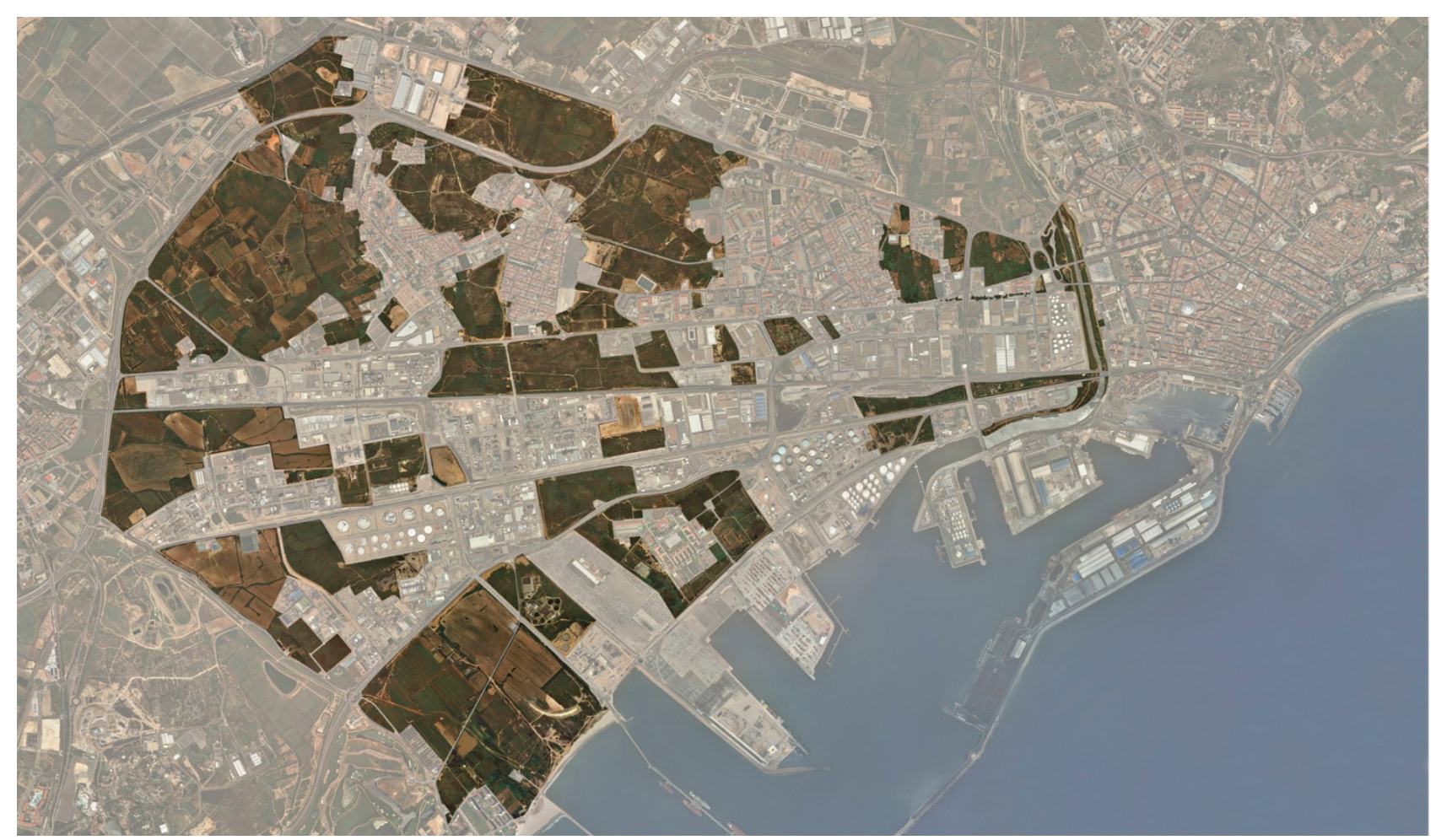

Fig. 4. Ortofotoplano modificado que ilustra el alcance de lo "no urbanizado" en ENTREVÍAS.

Fuente: Elaboración propia a partir de ortofotoplanos del ICC (2010)

Esta realidad nos conduce a considerar que a través de la existencia de una compleja relación, no exclusivamente industrial ni residencial, podríamos imaginar la poética de una pseudo-ciudad en ENTREVÍAS, toda vez completada la búsqueda de unos valores no únicamente periféricos y ejemplos de mayor influencia en la compensación de déficits urbanos que nos lleven a resaltar la sutil percepción de una urbanidad diferenciada, que incide en la identificación práctica de un sistema interconectado pero independiente a la vez. O de cómo el observador se hace suyo el espacio intersticial próximo a la industria y al puerto y lo identifica como territorio urbano de calidad en cuanto a su uso y no por su naturaleza.
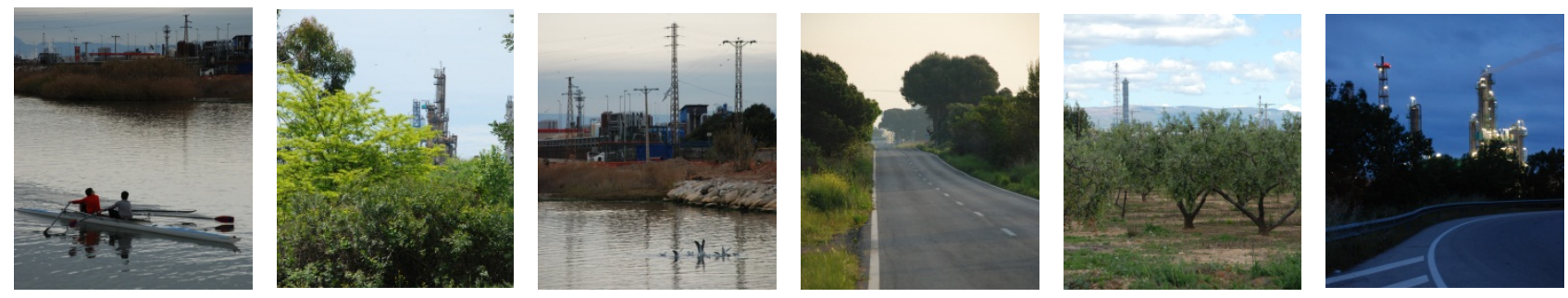

\section{Cuatro escenarios para entrevías.}

Los anteriores posicionamientos nos conducen a derivas no previstas ni inmediatas, pero sí sugerentes. La posibilidad de identificar y determinar una dinámica urbano-territorial predominante, alternativa a los criterios que han liderado y protagonizado la realidad urbanística en ENTREVÍAS y su entorno, es factible, permitiendo además comprender los orígenes de las permanencias en este territorio y los escenarios de la transitoriedad que conviven en este entorno. En este sentido, y a modo enunciativo, se proponen las siguientes hipótesis con un rápido acercamiento gráfico a todas ellas.

\subsection{N-340. La "Gran Vía" del Camp.}

¿Todas las urbanidades tienden a encontrarse? La bipolaridad entre Reus y Tarragona no tiende a encontrarse de forma lineal, no son urbanidades que se busquen. En contraposición a la promocionada T-11 (eje lineal Reus-

Cuatro escenarios para entrevías-Tarragona. ¿Cabría una dinámica dominante? Juan Manuel Zaguirre Fernández. DOI 10.14198/i2.2015.03.01 
Tarragona) el tramo de la antigua N-340 comprendido entre Vila-Seca y el río Francolí presenta mayores posibilidades de movilidad y conexión entre urbanidades que sí se "buscan" y otras en latente estado de reconversión, llamadas -todas ellas y en conjunto- a ser emergentes y vertebradoras del Camp de Tarragona. Lo avalan las diferentes secciones y usos que conviven actualmente a lo largo de este recorrido, así como toda suerte de frentes urbanos que se abren a esta vía, aportando un carácter diferenciado que permite obtener una rica secuencia de discontinuidades urbanas. La radicalidad de este trazado tiene también algo de centralidad lineal en paralelo. Entender el papel vertebrador de la N-340 es provocar una mirada diferente sobre los sucesos urbanísticos que paulatinamente se han desplegado en torno a esta traza, generalmente sin apoyarse sobre ella directamente. Asentamientos que obedecen a decisiones -no casuales- que han articulado este territorio a partir de una segregación de usos interesada, basada en las expectativas urbanísticas de un enclave industrial ideado lejos del territorio y en el marco de un desarrollismo desbocado. Resultará especialmente interesante analizar, por su especial bifurcación, el encuentro de la trama urbana de Tarragona con la N-340 al otro lado del cauce del Francolí. En 1923 la ciudad ya puso en valor este emplazamiento con la construcción del edifico para la Tabacalera en el margen derecho del Francolí, mejorado en 1930 por la implantación de CAMPSA en el margen opuesto.

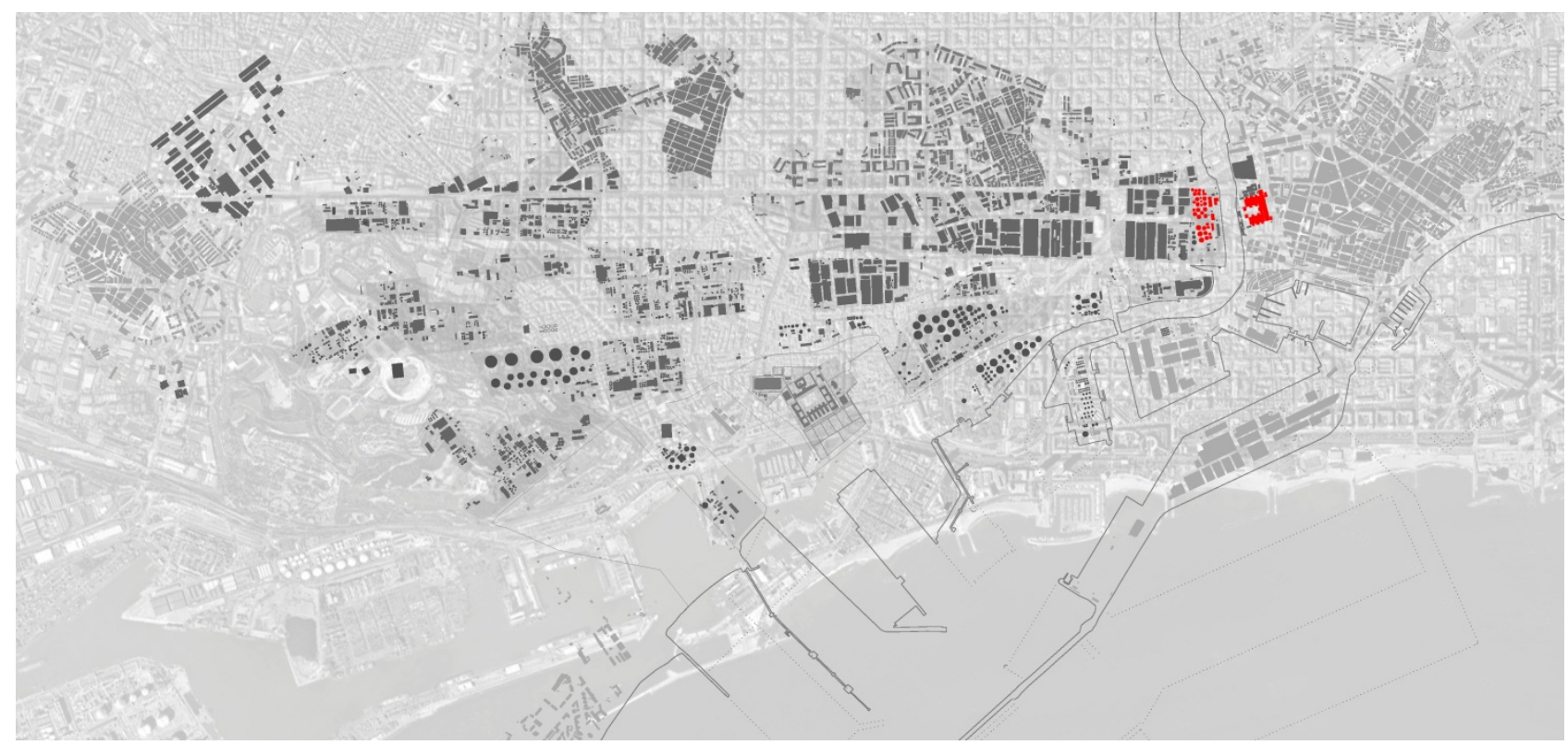

Fig. 6. Comparación de escala a través de la superposición cartográfica haciendo coincidir la N-340 con la "Gran vía" de Barcelona. Fuente: Elaboración propia a partir de cartografía y ortofotografía del ICC (2010). En rojo edificios de Tabacalera y CAMPSA.

\subsection{Entre el mar y ENTREVÍAS, el puerto.}

La influencia del puerto para ENTREVÍAS y sobre los límites confusos entre Tarragona y el mar es indiscutible, pero no hegemónica. Las cambiantes trazas que han delimitado la zona de afectación portuaria y los territorios de La Pineda y Polígono Sur dicen mucho sobre las tensiones urbanísticas a un lado y a otro de estas líneas, que todavía hoy siguen perfilando el complejo límite entre la influencia y las necesidades de la Autoridad Portuaria y los existentes usos limítrofes; el agrario, el turístico y el industrial. La forzada trabazón de los límites portuarios con su territorio más próximo presenta una discontinuidad visual, reflejo de la forzada juntura entre ambos territorios, por la difícil convivencia entre terrenos expectantes y necesidades portuarias en constante crecimiento. En definitiva, las prexistencias sobre los territorios de la franja costera se convierten en dinámicas que han REDIBUJADO LOS ESPACIOS DE RELACIÓN entre el puerto y su territorio más adyacente en forma de maclas. También un protagonismo compartido entre el puerto y la actividad industrial en ENTREVÍAS es la causa de la constante tensión entre ellos, produciendo apéndices construidos y vacíos intersticiales según varía la intensidad de dicho protagonismo. Esta alternancia de piezas macizas, huecas y expectantes, dispuestas a lo largo de este irregular límite físico y de forma acumulativa, ha articulado sucesivamente las actuaciones portuarias construidas hasta conseguir una estructura general no necesariamente homogénea ni coherente, pero tampoco conflictiva. Produciendo dinámicas urbanísticas que comparten mecanismos de composición urbana entrelazados, pero a la vez, separados y distantes. Generando mutaciones formales con repercusión directa en las posibilidades de conexión, implicación y relación. Permitiendo contradicciones entre usos limítrofes y cercanos. Estableciendo incertidumbres ante las consecuencias territoriales originadas por desequilibrios y carencias sin resolver. 

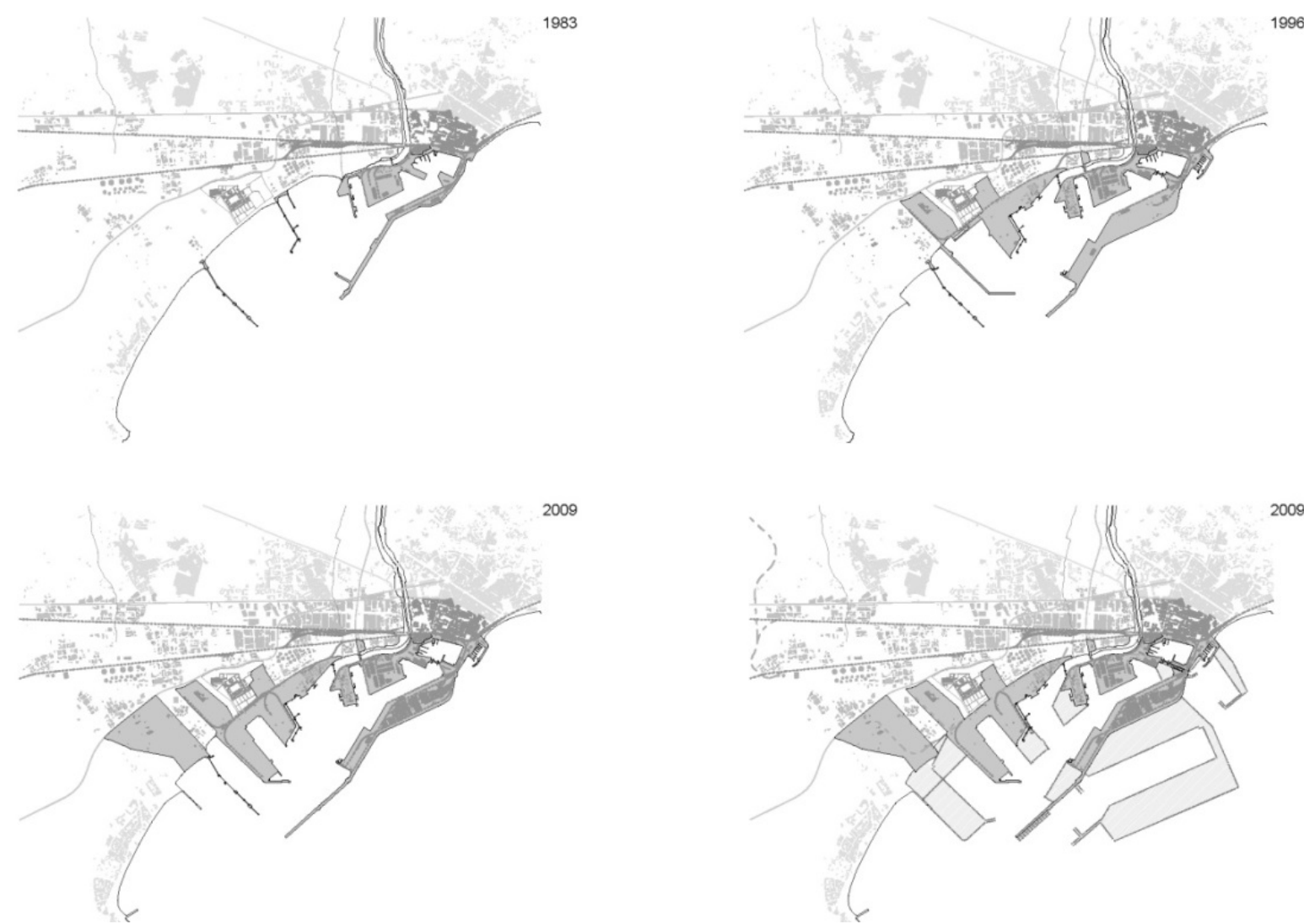

Secuencia cartográfica de crecimiento portuario 1983-2009 (y ampliaciones previstas) del puerto de Tarragona.

Fuente: Elaboración propia a partir de documentación cartográfica obtenida del Arxiu del Port de Tarragona. 2012

\subsection{La geometría generadora que producen las infraestructuras.}

Esta hipótesis de trabajo propone considerar a la gran traza infraestructural también como generadora de forma urbana. Nada hubiera sido igual en este territorio de no existir los trazados pasantes impuestos a partir de $1835 \mathrm{y}$ previos a cualquier intento colonizador tanto residencial como industrial. Líneas férreas, carreteras y posteriormente vías de alta capacidad han sugerido, todo este tiempo, un crecimiento urbano altamente condicionado. Esta geometría impuesta ha procurado también una jerarquización del suelo que, por su contundencia, ha contribuido a un autismo entre sectores periféricos y a la generación de huecos estancos "intraestructurales" ${ }^{3}$ que paulatinamente han sido ocupados con usos diversos en su mayoría.
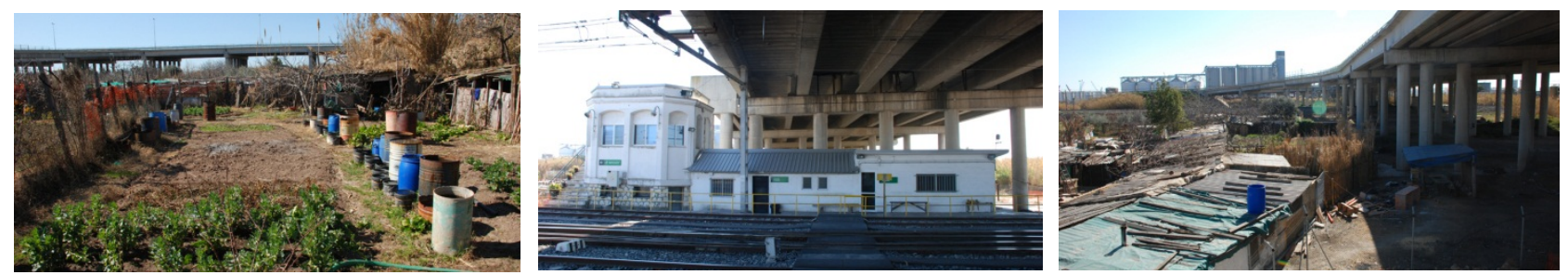

Fig. 7. Selección de imágenes de usos marginales en vacíos "intraestructurales" de Entrevías (2011) Fuente: Elaboración propia

Movimientos en el panorama infraestructural por la actualización, modernización y modificación de recorridos férreos y viarios, tendrán como consecuencia que algunas de estas actuales trazas sean reubicadas o incluso eliminadas. ¿Podría entonces verse alterado el tenso equilibrio urbanístico que ellas provocaron? La posible respuesta a esta pregunta ya justifica, por sí sola, la necesidad de profundizar en el desarrollo de esta hipótesis. Pero podemos anticipar ya que cualesquiera que sean las respuestas a esta pertinente pregunta no dejarán indiferentes al resto de escenarios propuestos. Antiguos trazados previstos y no construidos en el Plan Monravà

\footnotetext{
${ }^{3}$ Manuel de Solà-Morales en su artículo "Un camp de coses. Els buits de la metrópolis" (Revista AT\#19:03. Ed. COAC-Tarragona. 2009) advierte del carácter dramático que está adquiriendo el "intraestructulalismo" en el área central del Camp de Tarragona. Propone no sólo ordenar el "infraestructuralismo" sino planificar también el "intraestructuralismo".
}

Cuatro escenarios para entrevías-Tarragona. ¿Cabría una dinámica dominante? Juan Manuel Zaguirre Fernández. DOI 10.14198/i2.2015.03.01 
(1960) y en el Plan de Infraestructuras (1973) ya condicionaron en su momento las plusvalías y expectativas a un lado y a otro de dichas trazas.

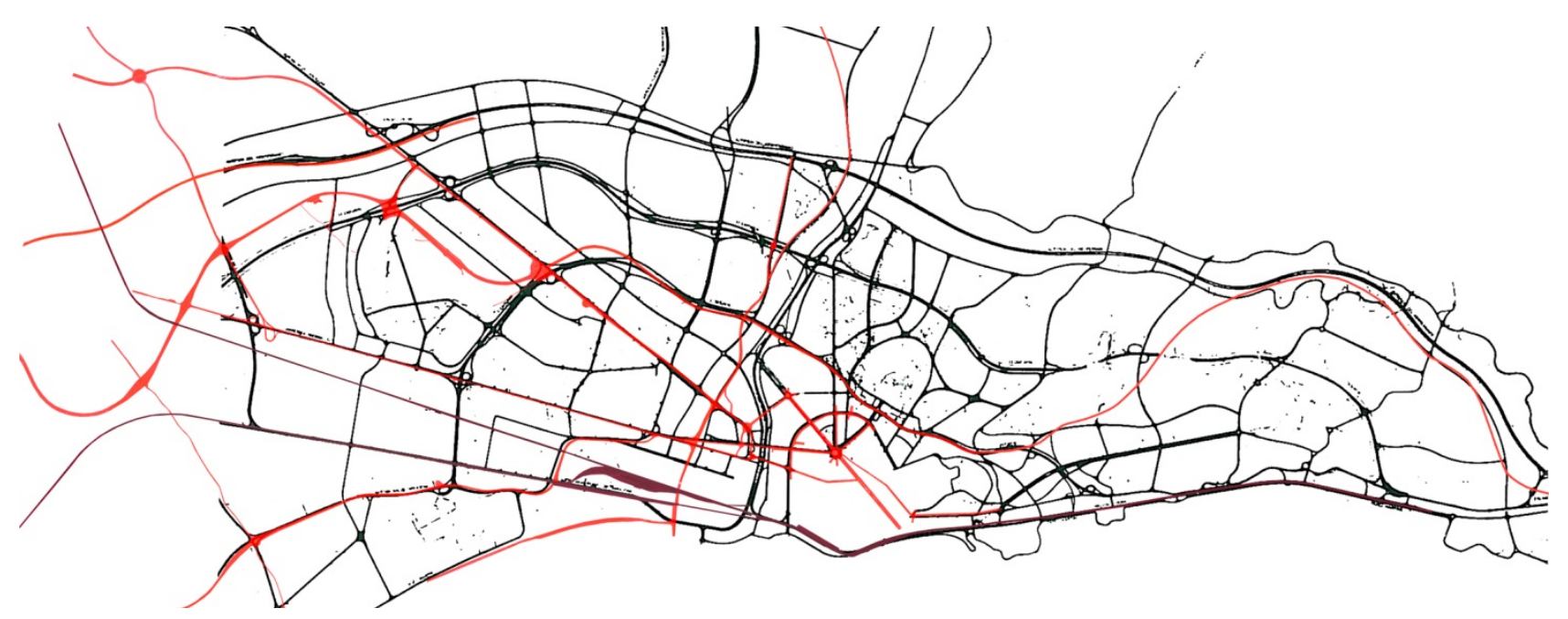

\subsection{ENTREVÍAS. Atributos y compromisos para una nueva urbanidad.}

ENTREVÍAS ha pasado en pocos años de ser un territorio agrícola y marginalizado por infraestructuras pasantes a ser motor esencial del desarrollo económico de la Tarragona moderna, anticipándose a las ampliaciones proyectadas desde 1922 y más cercanas al centro urbano de Tarragona. Dotada prematuramente de atributos de ciudad como; centralidades, mercados tradicionales, ensanches, polígonos, equipamientos, monumentalidades, nodos, periferia e infraestructuras diversas, ha adquirido un compromiso urbano que le confiere cierta autonomía en lo económico, pero sobre todo en lo social. Este reconocido peso estratégico aportado por ENTREVÍAS no se traduce en una percepción de poseer cierta entidad urbanística, todo lo contrario, la precariedad y marginalidad periférica -ligada al hecho industrial- han sido su apelativo más habitual. ¿Pero hasta qué punto esta realidad difusa puede llegar a consolidarse más allá de lo periférico? Este mundo completo ${ }^{4}$, de difícil catalogación, que es el Camp de Tarragona no responde a una metrópolis "al uso" y probablemente "su futuro feliz pasa por reconocer e inventar su propia figura metropolitana" (Solà-Morales, 2009). Para ello le será imprescindible disponer de una centralidad emergente que equilibre la realidad "policéntrica" del Camp. Toda hipótesis planteada en estos términos deberá demostrar la existencia de unas relaciones internas, con suficiente intensidad, para soportar esta relación sistémica entre los actores protagonistas de ENTREVÍAS, que sorprendentemente no lo han sido del Camp de Tarragona. Este reto académico pasa por identificar cada uno de estos protagonismos, y las relaciones entre ellos, a través de una puesta en común de los procesos urbanos que todos reconocemos como habituales en una ciudad moderna.

\footnotetext{
${ }^{4}$ Rafael Moneo, en su intervención como Presidente del Tribunal, definió al Camp de Tarragona como “(...) este mundo completo que es el Camp de Tarragona (...)" durante la lectura y defensa de la Tesis Doctoral "NOMÉS IMATGES. La tarjeta postal, vehicle de coneixement urbà". Autor, Sardà Ferran, Jordi.
}

Cuatro escenarios para entrevías-Tarragona. ¿Cabría una dinámica dominante? Juan Manuel Zaguirre Fernández. DOI 10.14198/i2.2015.03.01 


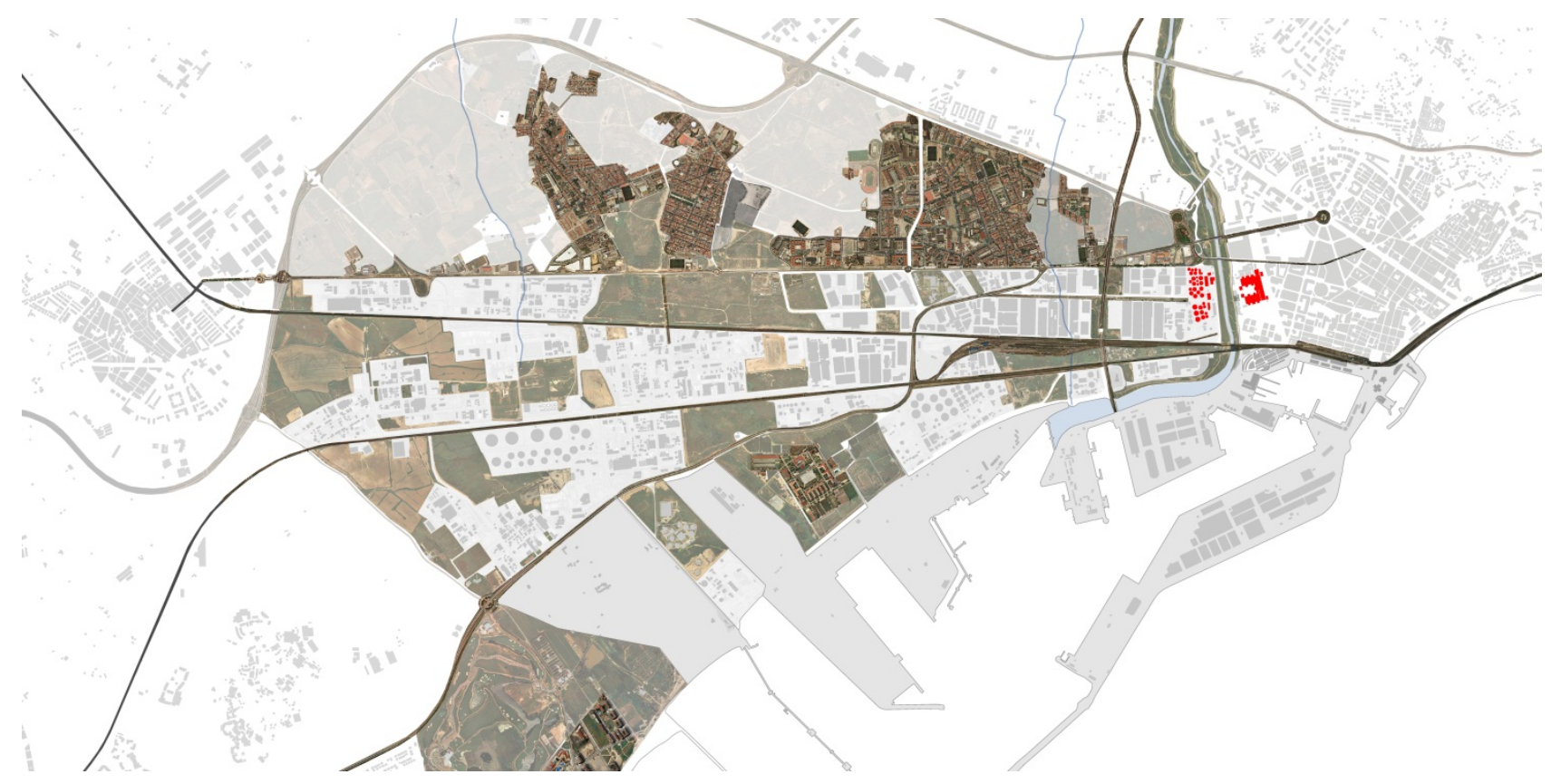

Fig. 9. Diferentes urbanidades, atributos, intersecciones, centralidades y espacios de oportunidad que coexisten en ENTREVÍAS. Fuente: Elaboración propia a partir de ortofotoplanos del ICC (2010)

\section{Conclusiones.}

Especular sobre la peculiar variedad urbana en ENTREVÍAS es quizás la mayor aportación que estos escenarios incorporan al debate abierto sobre el rumbo territorial de la conurbación de Tarragona, dónde la búsqueda de una dinámica o dinámicas dominantes puede convertirse en un certero impulso. El estudio en torno a estas cuatro hipótesis, y paralelamente al desarrollo de sus enunciados, ha sugerido ya una serie de preguntas como reacción a determinadas situaciones y relaciones urbanísticas detectadas al pretender empaquetar en grandes contenedores las derivadas urbanas en este territorio. Toda una muestra del avance de la investigación que va profundizando en un mayor conocimiento sobre ENTREVÍAS y de todo aquello que interviene e interfiere en su modelado, percepción y expectativas. Estas miradas atentas a través de particulares ventanas o puntos de vista suponen un reconocimiento implícito de las relaciones internas que conviven en ENTREVÍAS y de sus correspondencias sobre la conurbación de Tarragona. Un sistema por desgranar y definir del que se ocupará esta investigación en siguientes etapas y que ya insinúa las siguientes perspectivas más allá de estos escenarios. ¿Qué presión ejerce ENTREVÍAS sobre la actual dinámica urbana de Tarragona?, ¿Cuáles serán los protagonistas de estas interacciones?, ¿Hacia dónde tiende a desplazarse el centro de gravedad de Tarragona, hacia ENTREVÍAS (poniente) o hacia TERRES CAVADES (levante)? Sin afrontar estas cuestiones no sería prudente anticipar, más allá de estas proposiciones, definiciones territoriales usando neologismos banalizados que distorsionen el verdadero alcance territorial de este ámbito central del Camp de Tarragona.

\section{Bibliografía.}

ALEMANY, J. Port de Tarragona: Història i actualitat. Tarragona: L'Avenç, 1986.

DEL AMO, R. El impacto de la industria petroquímica en el medio rural. P. de Mafumet: Ajuntament, 1988.

HERNÁNDEZ, B.. Historia del puerto de Tarragona: desde su origen hasta nuestros días. Tarragona: Puerto, 2002.

LLOP TOUS, J. La industrialització de Tarragona (1957-1971). Tarragona: Arola, 2002

LLOVELL FORTUNY, F. La industrialización de Tarragona. Tarragona: AEQT, 1980.

MARGALEF, J. El Tarragonès, estructura econòmica: expansió industrial i desequilibris sectorials. Barcelona: Caixa de Catalunya, 1979.

MONTEJANO, J. A. Metropolización del Territorio y Regiones Urbanas Medias. El caso del ámbito central del Camp de Tarragona, 1977-2008. Barcelona: Tesis Doctoral-UPC, 2010.

PARCERISA, J. Forma Urbis. Cinco ciudades bajo sospecha. Barcelona: LUB, 2012.

PUJADAS, J. Los Barrios de Tarragona: una aproximación antropológica. Tarragona: Ajuntament, 1987.

SOLA-MORALES, M. Territoris sense model". En PAPERS no 26 (21-27). Barcelona: RMB

1997. - Un camp de coses (els buits de la metròpolis). Revista AT (Tarragona), 19, 3, 2009. 